\title{
Обцественная опасность и критерии ее оценки
}

\author{
P. В. КИЛИМБАЕВ - командир взвода юридического факультета Академии \\ ФСИН России
}

Р е ферат

Общественная опасность является основополагающим признаком любого преступления, но к настоящему времени законотворческой практикой не выработан алгоритм для определения наличия или отсутствия в деянии общественной опасности, достаточной для того, чтобы признать его преступным. Среди исследователейправоведов также отсутствует единство мнений в вопросах о сущности общественной опасности деяния и критериях ее определения. Все это порождает включение в уголовное законодательство норм, предусматривающих ответственность за деяния, общественная опасность которых весьма условна. На основе изученных материалов в данной работе сформулированы критерии, установление совокупности которых позволяет признать деяние общественно опасным и, как следствие, уголовно наказуемым.

Ключев ые слова: преступление; признаки уголовно наказуемого деяния; общественная опасность; противоправность; критерии общественной опасности; юридическая конструкция.

12.00.08 - Уголовное право и криминология; уголовно-исполнительное право

\section{Public danger and criteria for its assessment}

R. V. KILIMBAEV - Platoon commander of the Law Faculty of the Academy of the Federal Penal Service of Russia

Abstract

Public danger is a fundamental sign of any crime, but to date law-making practice has not developed an algorithm to determine the presence or absence of a public danger in an act sufficient to recognize it as criminal. Among legal scholars there is also a lack of consensus on issues of the essence of the social danger of an act and the criteria for its determination. All this gives rise to the inclusion in the criminal law of norms providing for liability for acts whose social danger is very conditional. On the basis of the materials studied in this work criteria are formulated, the establishment of the totality of which allows recognizing the act as socially dangerous and, as a consequence, criminally punishable.

Ke y w ord s: crime; signs of a criminal offense; public danger; wrongfulness; criteria of public danger; legal construction.

12.00.08 - Criminal law and criminology; penal law 
За достаточно продолжительный период времени в доктрине уголовного права (возможно, и во всей теории права) сложилось устойчивое представление о преступлении как деянии, обладающем уникальным признаком - общественной опасностью. Современный уголовный кодекс, равно как и предыдущие нормативные источники отечественного уголовного права, называет общественную опасность одним из признаков преступления (ч. 1 ст. 14 УК РФ). Это обстоятельство, бесспорно, свидетельствует о высокой значимости определения общественной опасности для решения вопроса о необходимости (либо отсутствии таковой) криминализации соответствующего деяния. Именно термин «общественно опасное деяние» используется в базовых положениях уголовного законодательства об установлении и реализации уголовной ответственности: принцип вины (ч. 1 ст. 5 УК РФ), принцип справедливости (ч. 1 ст. 6 УК РФ), а также определение времени совершения преступления (ч. 2 ст. 9 УК РФ), основание для отнесения вида преступления к той или иной категории (ч. 1 ст. 15 УК РФ) и др.

Однако, несмотря на важность общественной опасности для обеспечения процесса криминализации деяния, современная наука уголовного права до настоящего времени не предложила универсального подхода к определению природы общественной опасности, хотя многие из исследователей предпринимали попытки поиска решения данной проблемы. С некоторыми оговорками все имеющиеся в современной научной литературе суждения о природе и содержании общественной опасности деяния, запрещенного уголовным законодательством или имеющего действительный потенциал для криминализации, можно подразделить на социологические (криминологические), правовые, техникоюридические.

Социологический (криминологический) подход к определению природы общественной опасности предоставляет достаточно широкие возможности в установлении границ изучаемого феномена [11, с. 107-108]. Отдельные исследователи рассматривали общественную опасность в качестве основания осуществления межотраслевой дифференциации юридической ответственности, составляющей уголовно-правового принципа справедливости, критерия выбора вида и размера (срока) уголовного наказания, условия применения поощрительных норм.
Дефиниции общественной опасности в действующем уголовном законе не содержится, что позволяет многим авторам формулировать ее путем буквального и расширительного толкования используемых законодателем терминов: общественная социальная; опасность - вредоносность и др. Юридическая неопределенность пределов общественной опасности как признака преступления породила выдвижение различных, иногда противоположных суждений относительно ее социальной сущности. Так, некоторые авторы утверждают, что общественная опасность является определяющим объективным свойством любого преступления [5, с. 606-607] или объективной вредоносностью деяния и последствий его совершения [9, с. 56].

Мнение о необходимости определения общественной опасности деяния только путем оценки его объективных признаков представляется дискуссионным, поскольку перечисленные критерии явно недостаточны для криминализации, что подтверждается анализом действующих норм Особенной части как отечественного, так и зарубежного уголовного законодательства. Достаточно большое число деяний признаются преступными только в случаях их умышленного совершения. Напротив, совершение тождественных действий по неосторожности влечет за собой отказ в признании общественной опасности деяния и, как следствие, его уголовной противоправности. Например, умышленное совершение уклонения от уплаты налогов при наличии иных юридически значимых признаков влечет за собой наступление уголовной ответственности по ст. 198 или 199 УК РФ, тогда как совершение налогоплательщиком или его представителем аналогичного деяния по неосторожности или невиновно исключает общественную опасность независимо от суммы неуплаченных налогов. Более того, дифференциация вины по форме существенно меняет общественную опасность деяний, тождественных по своим объективным признакам, что можно заключить, исходя из анализа санкций, например, ч. 1 ст. 105 и ч. 1 ст. 109 УК РФ: за умышленное лишение человека жизни минимальный размер лишения свободы составляет шесть лет, тогда как за аналогичное деяние, совершенное по неосторожности, наиболее суровое наказание определяется двухлетним сроком лишения свободы.

Разновидностью рассматриваемого подхода к определению социальной природы общественной опасности является ее ка- 
чественное соотношение с преступностью деяния: последнее признается уголовно наказуемым только в том случае, если устанавливается его общественная опасность. Это позволило отдельным авторам утверждать, что в процессе осуществления законотворческой деятельности производится оценка на предмет наличия общественной опасности, достаточной для принятия положительного решения об официальном признании конкретного деяния преступлением. Во всех других случаях не представляется возможным выявить природу преступного поведения виновного лица [10, с. 91].

Несмотря на абсолютную логичность представленного решения по определению общественной опасности деяния на первоначальных стадиях правотворчества, в научной литературе не без оснований высказываются опасения относительно реальной возможности практического установления факта общественной опасности на любой из стадий нормотворческого процесса. Coмнения состоят в том, что законодатель не обладает сверхъестественной проницательностью, с помощью которой среди всего многообразия видов человеческого поведения способен установить незначительный круг деяний, обладающих общественной опасностью, равно как и сверхъестественной расторопностью в принятии решения об их криминализации [3, с. 8]. Однако это не снимает проблему необходимости формулирования предложений о приемлемых вариантах установления общественной опасности деяния на первоначальных стадиях законотворческого процесса, поскольку неопределенность в данном вопросе исключает возможность перехода к следующим стадиям нормотворчества, на которых определяется совокупность юридически значимых признаков деяния, бесспорно обладающего общественной опасностью.

Другая группа ученых считает, что первоочередным признаком преступления является его уголовная противоправность. Исходя из этого общественной опасностью обладает то деяние, совершение которого запрещено соответствующей нормой уголовного закона. В свою очередь, если деяние не предусматривается УК РФ, то оно не обладает общественной опасностью, достаточной для криминализации [6, с. 41; 8, с. 117-122].

Состоятельность, как и логическая обоснованность, высказанного мнения ставились некоторыми представителями уголовно-правовой доктрины под сомнение. В частности, дискуссионность этого предложения по определению общественной опасности виделась в том, что законодатель не способен по собственному волеизъявлению менять социальную сущность деяния, наделяя его общественной опасностью или лишая ее в процессе принятия или исключения соответствующих норм уголовного закона [1, с. 38-39]. Кроме того, А. Э. Жалинский, критикуя подобный формалистский подход, указывал на недопустимость фактического отказа от осмысления и оценки общественной опасности деяния на том основании, что оно уже нашло законодательное закрепление [4, с. 229].

Полностью соглашаясь с позицией А. Э. Жалинского, дополнительно отметим, что определение общественной опасности на основании состоявшегося факта признания деяния преступлением не в полной мере соответствует одному из правил формальной логики о причине и следствии. Так, деяние изначально должно быть признано общественно опасным, что и будет основанием для его последующего официального признания преступлением. В противном случае общественная опасность может устанавливаться применительно к любому виду закрепленных в уголовном законе деяний, что в отдельных случаях далеко не бесспорно (ст. 130, 200 УК РФ, а также ч. 1 ст. 169, 138.1, 172.1 УК РФ и др.). Поэтому для недопущения случаев включения в уголовное законодательство видов деяний, явно не обладающих достаточной для преступления общественной опасностью, необходимо изначально решить проблему о тех критериях общественной опасности, совокупность которых гарантированно обеспечит установление основания для последующей криминализации. Думается, что данная задача останется неразрешимой в условиях применения социологического (криминологического) анализа онтологии общественной опасности по причине высокой степени абстрактности и противоречивости получаемых в результате изучения характеристик.

Юридический (формально-юридический) подход к определению общественной опасности предполагает наличие ее официального толкования. Российский уголовный закон содержит только дефиницию преступления, одним из признаков которого выступает общественная опасность. В то же время общественная опасность, будучи уголовно-правовой категорией, законом не определяется, хотя наделение ее четкой 
дефиницией имеет существенное практическое значение.

Значимость выделения критериев общественной опасности в настоящее время признана Пленумом Верховного Суда Российской Федерации, который в постановлении от 22.12.2015 № 58 перечисляет юридически значимые факты, определяющие характер и степень общественной опасности преступления: признаки состава преступления, направленность деяния, причиненный вред, способ совершения преступлении и др. Однако этого явно недостаточно, поскольку столь важный вопрос должен решаться на уровне уголовного закона, то есть нормативного акта, признаваемого источником отрасли уголовного права. Анализ перечисленных характеристик позволяет провести аналогию с содержанием элементов состава преступления, установление которых в совершенном деянии является обязательным условием для привлечения лица к уголовной ответственности (ст. 8 УК РФ).

Учитывая перечисленные обстоятельства, считаем, что наиболее рациональное предложение по поводу юридического содержания общественной опасности и ее определения в процессе правотворческой деятельности сформулировано А. Э. Жалинским. Он рассматривал все закрепленные в ч. 1 ст. 14 УК РФ признаки преступления исключительно в качестве юридических конструкций [7, с. 350], а не социальных или правовых явлений. Общественная опасность, по мнениюА. Э. Жалинского, является юридической конструкцией и определяется путем установления совокупности взаимодействующих друг с другом системных элементов - состава общественной опасности, который отражает факты реальной действительности, описанные на языке права. Отсутствие возможности установления одного или нескольких элементов общественной опасности влечет за собой принятие решения о ее отсутствии в соответствующем деянии, то есть отсутствии преступления. На этом основании автор предлагает выделять следующие элементы состава общественной опасности: 1) охраняемое правовое благо и его признаки: социальную ценность, уязвимость и возможность охраны; 2) посягательство как объективную сторону деяния и его признаки: насилие, обман, пренебрежение обязанностями или долгом; 3) нарушение социальных благ и интересов и его признаки: реальную опасность благам, угрозу, вред различного содержания и интенсивности [4, с. 235].
Предложенный перечень элементов является исчерпывающим. В этой связи обращает на себя внимание факт отказа от включения в систему элементов состава общественной опасности вины (формы и вида). Наличие объективных характеристик нарушаемых общественных отношений, деяния, его последствий и т. п. не во всех случаях определяет наличие общественной опасности, достаточной для криминализации соответствующего деяния. Выработанные уголовно-правовой наукой характеристики вины имеют не менее важное значение по сравнению с объективными признаками общественной опасности деяния, в связи с чем обязательно должны учитываться при определении ее характера и типовой степени [2, с. 159].

Несмотря на непризнание исследователем вины самостоятельным элементом, значение предложенной им системы переоценить невозможно. Общественная опасность является базовым началом для характеристики деяния как преступного, поэтому установление социальной природы общественной опасности любого поведения на ранних стадиях нормотворческого процесса позволит существенно снизить степень возможности криминализации деяний, в действительности не обладающих общественной опасностью. Ясное представление об элементах общественной опасности деяния, признанного преступлением, повысит технико-юридическое качество уголовно-правовых норм, устанавливающих ответственность за его совершение. В диспозиции нормы Особенной части УК РФ будет необходимо конкретизировать каждый из элементов общественной опасности деяния и выстроить их в иерархическом порядке в зависимости от значимости нарушаемых социальных благ и интересов.

Определение общественной опасности деяния путем обозначения и последующего установления совокупности характеризующих ее элементов имеет важное практическое значение. Осуществляемая подобным путем оценка наличия общественной опасности, достаточной для последующей криминализации соответствующего деяния, значительно облегчается ввиду относительной простоты, сочетающейся с универсальностью и строгостью последовательности установления каждого из входящих в конструкцию элементов.

Использование данного подхода при определении общественной опасности если не исключает, то сводит к минимуму воз- 
можность необоснованной криминализации соответствующего деяния, в котором отсутствует тот или иной элемент устанавливаемой юридической категории.

Факт наличия в деянии общественной опасности является основанием для создания конструкции состава преступления, что существенно облегчает процесс правотворческой деятельности, поскольку почти каждый элемент общественной опасности корреспондирует соответствующему элементу конструкции состава преступления.

Рассмотрение общественной опасности деяния в качестве разновидности юридической конструкции дает ряд существенных преимуществ, таких как:

- универсальность применения к любому виду посягательства на охраняемые уголовным законом общественные отношения;

- типизация элементов, совокупность которых образует юридическую конструкцию общественной опасности, позволяющая точно определить границы анализа общественной опасности деяния;

- исключение возможности необоснованной криминализации деяния;

- упорядочение законотворческого процесса, обеспечение логичности и обоснованности принимаемых решений о криминализации деяния. Построение состава преступления представляет собой уточнение и (или) конкретизацию содержания элементов ранее установленной общественной опасности деяния (действия или бездействия).

Таким образом, среди всего многообразия доктринальных предложений по определению сущности общественной опасности наиболее рациональным и перспективным для уголовного правотворчества следует признать реализуемый А. Э. Жалинским технико-юридический подход, в соответствии с которым общественная опасность преступления представляет собой юридическую конструкцию. Содержание элементов данной юридической конструкции (общественные отношения, предметом которых является охраняемое правовое благо; общественно опасное деяние; нарушение социальных благ и интересов; форма и вид вины, которыми характеризуется совершаемое деяние) во многом совпадает с перечнем соответствующих признаков состава преступления, что позволяет установить внутреннюю взаимосвязь между общественной опасностью и противоправностью и исключает возможность искусственного конструирования состава преступления при отсутствии общественной опасности запрещаемого уголовным законом деяния.

\section{СПИСОК ЛИТЕРАТУРЫ}

1. Блувштейн, Ю. Д. Основания криминологии: опыт логико-философского исследования / Ю. Д. Блувштейн, А. В. Добрынин. - Минск : Университетское, 1990. - 208 с. - ISBN 978-5-7855-0463-4.

2. Бочкарев, С. А. О природе общественной опасности преступления / С. А. Бочкарев // Бизнес в законе. - 2009. - № 5. - С. 155-159.

3. Гонтарь, И. Я. Категория общественной опасности в российском уголовном праве: история становления и современное понимание / И. Я. Гонтарь // История государства и права. - 2008. - № 2. - С. 7-10.

4. Жалинский, А. Э. Общественная опасность преступления в структуре уголовно-правовой оценки деяния / А. Э. Жалинский // Избранные труды : в 4 т. Т. 2. Уголовное право. - Москва : Высшая школа экономики, 2015. C. 225-231. - ISBN 978-5-7598-1213-5.

5. Лапшин, В. Ф. Социальные основания для определения признака общественной опасности преступного деяния / В. Ф. Лапшин // Цивилизация знаний: российские реалии : сборник трудов XVII Международной научной конференции. - Москва : РосНОУ, 2016. - С. 606-608.

6. Малков, В. П. Характер и степень общественной опасности преступлений в системе общих начал назначения наказания / В. П. Малков // Российская юстиция. - 2008. - № 9. - С. 41-45.

7. Морозова, Л. А. Теория государства и права : учебник / Л. А. Морозова. - Москва : Норма, 2018. - 464 с. ISBN 978-5-91768-844-2

8. Наумов, А. В. Российское уголовное право : курс лекций : в 2 т. Т. 1. Общая часть / А. В. Наумов. - 3-е изд., перераб. и доп. - Москва : Юридическая литература, 2004. - 495 с. - ISBN 978-5-7260-1022-1.

9. Новоселов, Г. Без преступных последствий нет преступления / Г. Новоселов // Российская юстиция. - 2001. № 3. - С. 56.

10. Уголовное право России. Часть Общая : учебник / отв. ред. Л. Л. Кругликов. - 3-е изд., перераб. и доп. - Москва : Проспект, 2013. - 563 с. - ISBN 978-5-392-09354-0.

11. Филимонов, В. Д. Принципы уголовного права / В. Д. Филимонов. - Москва : Центр ЮрИнфоР, 2002. - 138 с. - ISBN 978-5-89158-097-7.

\section{REFERENCES}

1. Bluvshtejn YU. D., Dobrynin A. V. Osnovaniya kriminologii: opyt logiko-filosofskogo issledovaniya [The basis of criminology: the experience of logical and philosophical research]. Minsk, 1990. 208 p. (In Russ.)

2. Bochkarev S. A. O prirode obshchestvennoj opasnosti prestupleniya [On the nature of the public danger of crime]. Biznes v zakone - Business in law, 2009, no. 5, pp. 155-159. (In Russ.).

3. Gontar' I. YA. Kategoriya obshchestvennoj opasnosti v rossijskom ugolovnom prave: istoriya stanovleniya i sovremennoe ponimanie [Category of public danger in the Russian criminal law: history of formation and modern understanding]. Istoriya gosudarstva i prava - History of State and Law, 2008, no. 2, pp. 7-10. (In Russ.). 
4. ZHalinskij A. E. Obshchestvennaya opasnost' prestupleniya v strukture ugolovno-pravovoj ocenki deyaniya [The public danger of crime in the structure of the criminal law assessment of an act]. Izbrannye trudy: $v 4 t$. T. 2. Ugolovnoe pravo [Selected works in 4 vol. Vol. 2. Criminal law]. Moscow, 2015, pp. 225-231. (In Russ.).

5. Lapshin V. F. Social'nye osnovaniya dlya opredeleniya priznaka obshchestvennoj opasnosti prestupnogo deyaniya [Social grounds for determining a sign of public danger of a criminal act]. Sbornik trudov XVII Mezhdunarodnoj nauchnoj konferencii "Civilizaciya znanij: rossijskie realii" [Proceedings of the XVII International Scientific Conference "The Civilization of Knowledge: Russian Realities"]. Moscow, 2016, pp. 606-608. (In Russ.).

6. Malkov V. P. Harakter i stepen' obshchestvennoj opasnosti prestuplenij v sisteme obshchih nachal naznacheniya nakazaniya [The nature and degree of public danger of crimes in the system of general principles of sentencing]. Rossijskaya yusticiya - Russian justice, 2008, no. 9, pp. 41-45. (In Russ.).

7. Morozova L. A. Teoriya gosudarstva i prava [Theory of Government and Law]. Moscow, 2018. 464 p. (In Russ.).

8. Naumov A. V. Rossijskoe ugolovnoe pravo : v 2 t. T. 1. Obshchaya chast' [Russian criminal law in 2 vol. Vol. 1. General Part]. Moscow, 2004. 495 p. (In Russ.).

9. Novoselov G. Bez prestupnyh posledstvij net prestupleniya [There is no crime without criminal consequences]. Rossijskaya yusticiya - Russian justice, 2001, no. 3, p. 56. (In Russ.).

10. Kruglikov L. L. (red.) Ugolovnoe pravo Rossii. CHast' Obshchaya [The criminal law of Russia. Part General]. Moscow, 2013. 563 p. (In Russ.).

11. Filimonov V. D. Principy ugolovnogo prava [Principles of Criminal Law]. Moscow, 2002. 138 p. (In Russ.). 